\title{
Reflexives and Reciprocals in English and Modern Standard Arabic: An Investigation and a Comparison
}

\author{
Shaimaa Darwish \\ Al-Azhar University, Egypt
}

\begin{abstract}
The aim of this paper is to investigate the typology of reflexives and reciprocals in English and MSA, which is a variety of standardized, literary Arabic used throughout Arab countries. It has shown that MSA morphologically encoded reflexives and reciprocals are in fact syntactically and semantically asymmetrical. It will be argued that morphologically encoded reflexives do not project an anaphor (an internal argument) syntactically and their morphological marker semantically serves as a reflexivizer, whereas morphologically encoded reciprocals do project an anaphor syntactically, realized either overtly or covertly. Concerning the distribution of such anaphor, the paper elucidates the admissible and in admissible environments. It is argued that MSA does not allow possessive reflexives, but allow possessive reciprocals such as the construct-state, whether it be a noun phrase or a locative prepositional phrase. This variation is accounted for by assuming that reciprocals occupy Spec of DP and therefore can be bound by an NP from a higher phase, whereas reflexives occupy a position lower than the D head and thus must be bound within their DP phase. Finally yet importantly, MSA override reflexives and reciprocals unlike their English counterparts, are always subject to the Principle A of the Binding Theory.
\end{abstract}

Index Terms — reflexives, reciprocals, Binding Theory, locative possessive

\section{INTRODUCTION}

In natural language, both reflexives and reciprocals have often been grouped under the umbrella term of 'anaphor' to simplify descriptions and analyses. They represent different, but related, linguistic concepts. Reflexives can be applied to self-directed subjects (Ndimele, 1999, P. 194). Namely, a participant acts on himself or herself, rather than on any other (x hits x). Reciprocals, on the other hand, are expressions that indicate that the subject of the verb is at the same time the object. Unlike reflexives, reciprocals require a plural subject, each acting on the other, (i.e., $\mathrm{x}$ acting on y and $\mathrm{y}$ acting on $\mathrm{x}$ ). They introduce a distributing element (each) into the meaning (Gaby, 2008, Heine \& Miyashita, 2008; and Kemmer 1993).

The paper is divided into four main sections. Section (1) defines reflexives and reciprocals. Sections (2) and (3) present an overview of this anaphora in English and MSA. Section (4) investigates the thematic and case marking in both constructions. Section (5) discusses short, medium and long-distance reflexives s and reciprocals. In sections (6) and (7), an analysis of override reflexives and reciprocals, besides locative possessive is given. The last section concludes and sums up the results of the study

\section{REFLEXIVES: AN OVERVIEW}

Languages differ in the way they express these two linguistic concepts; for example, although the encoding of reflexives and reciprocals in both English and Modern Standard Arabic (MSA) may be parallel at some levels, it is different at some other levels. A predicate in general may be reflexive-marked in the following three distinct ways: (i) one of its arguments (NP/DP) appears as what Reinhart and Reuland (1993) call a Self-anaphor, (ii) the predicate itself (typically a verb) is lexically/inherently reflexive, or (iii) the predicate is specified as reflexive through overt morphological marking. The first mechanism has been referred to by Reinhart and Reuland (1993, p. 693) as "Extrinsic" reflexivization, and the latter two as "Intrinsic" reflexivization.

Reflexivity in English can be expressed in either way with its intrinsic reflexivity but not being marked by any overt morphology Napoli (1996), as exemplified in (1) and (2).

(1) The little girl liked herself $_{1}$.

In the above example, the predicate liked is extrinsically reflexivized when its object argument appears as the reflexive anaphor herself. An English reflexive (e.g. herself) is a morphologically complex object that consists of a root Self and a pronominal prefix. It consists of local reflexives appearing in argument position, usually as a co-argument of the same verb as its antecedent (Stern, 2004). The reflexive pronoun herself is co-referential with its antecedent the little girl; it agrees with it in person, number and gender and occurs to the right of it (Carnie, 2012). The interpretation of the reflexive pronoun in (1) is referentially dependent on its subject argument the little girl. 
(2) The little girl behaved.

In (2) the predicate behaved is intrinsically reflexive due to its lexical meaning, which is not indicated by any overt morphology on the verb.

Both extrinsic and intrinsic methods of reflexivization can also be combined, as illustrated in (3).

(3) The little girl $_{1}$ behaved herself 1

In this example, the predicate behaved as an intrinsically reflexive predicate is accompanied by the self anaphor herself as its object. Note that this double encoding of reflexivity in English involves a lexically inherent (bare) verb and an anaphor).

In MSA, verbs can be reflexive-marked in three ways: using a self anaphor which turns a transitive verb into an extrinsic reflexive or using verbs that are inherently reflexive (e.g., /halaqd 'shaved') or verbs having an overt morphological marker (e.g., /Pistahamma/ 'bathed') (intrinsic reflexive). It is worth noting that the use of intrinsic reflexives in this paper includes only MSA morphologically encoded predicates, but does not include inherently reflexive predicates.
(4) a. / Palwaladu hammama nafsahu $_{1} /$.
The boy.NOM bathed himself.ACC
'The boy bathed himself.
b. /Palwaladu Pistahamma/.
The boy.NOM bathed.ST
'The boy bathed.' (= 'The boy bathed himself.')

The verb in (4a) is extrinsically reflexive-marked by the anaphor /nafsahu/'himself'. Notice that the reflexive anaphor is used with a transitive verb and reflexivity is consequently achieved through binding; the verb /hammama/ 'bathed' is then a syntactically encoded reflexive. While the verb in (4b) becomes "intrinsically" reflexive by virtue of the morphological marker -/st/, which functions as a reflexivizer. Notice that the verb /?istahamma/ 'st.bathed' becomes intransitive. Unlike English, MSA disallows the double encoding of reflexivity, as shown in (5). It must, however, be borne in mind that the MSA reflexive verbs involve overt morphology.
(5) a. */Palwaladu 1 ta Paddaba nafsahu $1 /$
The boy.NOM TA.behaved himself
'The boy behaved (himself).
b. */Palwaladu 1 Pistahamma/ nafsahu 1 /.
the boy.NOM sT.bathed himself
'The boy bathed himself.'

The starred sentences in (5a and $5 \mathrm{~b})$ are ungrammatical, since morphologically encoded reflexive verbs such as /taPaddaba/'TA.behabed' and/ Pistahamma/'IST-'bathed' are intransitive, namely, verbs that project only one subject argument syntactically. Thus, such reflexive configuration cannot be structurally generated in MSA. The structural typology of reflexive constructions in English and MSA is summarized in the table below:

TABLE 1

TYPOLOGY OF REFLEXIVE CONSTRUCTIONS IN ENGLISH AND MSA)

TYPOLOGY OF REFLEXIVE CONSTRUCTIONS IN ENGLISH AND MSA)
\begin{tabular}{|l|l|l|}
\hline Linguistic elements In English & Linguistic elements In MSA & Modes of linguistic encoding \\
\hline $\begin{array}{l}\text { Inherently reflexive verbs } \\
\text { behave }\end{array}$ & $\begin{array}{l}\text { Inherently reflexive verbs } \\
\text { e.g., /halaqa 'shaved' }\end{array}$ & Lexical \\
\hline- & $\begin{array}{l}\text { Reflexivizing morphemes } \\
\text { ta-, }-n-, t-,- \text { st- }\end{array}$ & Morphological \\
\hline $\begin{array}{l}\text { Self anaphors } \\
\text {-self }\end{array}$ & $\begin{array}{l}\text { Self-anaphors } \\
\text { e.g., /nafs-/'-self' }\end{array}$ & Syntactic \\
\hline
\end{tabular}

\section{RECIPROCALS: AN OVERVIEW}

Regarding reciprocal, it may be encoded across languages lexically, morphologically and syntactically. Each of such modes of linguistic encoding may be realized by using one or more syntactic categories. In English, lexical encoding of reciprocals may include nominal elements (e.g., spouses, friends, neighbors) or verbal elements (e.g., meet, gather, fight), which lexically exhibit a mutual association among participants. That is, the meaning of such elements implies or encompasses a mutual and hence reciprocal relation.

Another linguistic mode of encoding reciprocals is syntactic in nature as it involves the use of a reciprocal anaphor like each other that is bound by an antecedent, as shown in' The two boys $<1+2>$ greeted each other $<1 \leftrightarrow 2>$ '.

Reciprocality may also be encoded by a modifier (an adverb) in English as exemplified in John and Mary are playing together. $\rightarrow$ Adverbial strategy (Implied meaning: John is playing with Mary and vice versa). Moreover, it can also be linguistically expressed by using multiple sentences e.g. He glimpsed her and she glimpsed him, or multiple propositions as in The boy talked to the girl and she talked to him (Maslova, 2000, Heine \& Kuteva, 2002; König \& Kokutani, 2006; Evans, 2008 ; Hicks, 2008) and Haas, 2010). This strategy involves at least two predicates. However, it is less common in languages such as English and Arabic wherein mutuality can be expressed in one proposition or clause; this is perhaps due to reasons of economy. 
In MSA, reciprocality can be expressed in three ways using a reciprocal anaphor or having a morphological marker (e.g., ta-) on the verb or both. Consider the following examples:

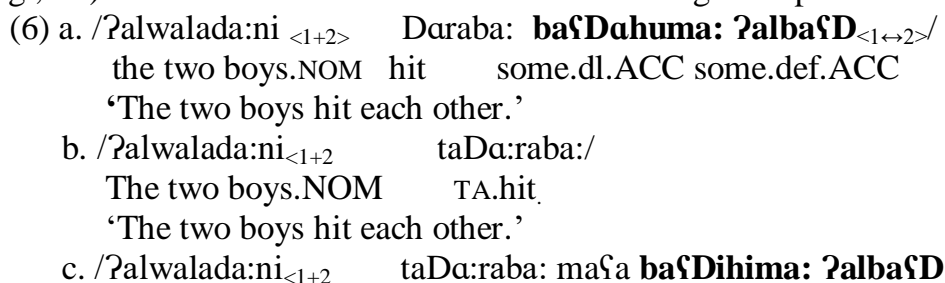

c. / Palwalada:ni $i_{<1+2}$ taDa:raba: maSa baSDihima: ?albaSD ${ }_{<1 \leftrightarrow 2>} /$. $_{\text {. }}$

the two boys.NOM TA.hit with some.dl.GEN some.def.GEN

'The two boys hit each other.'

Since reciprocality is semantically characterized as a mutual binary relation between/among at least two participants in an eventuality, the subject arguments in (a) bind the reciprocal pronouns. Interestingly, the predicate/ Daraba: / 'hit' in (a) is not inherently reciprocal; rather, it is only reciprocal by virtue of their co-indexed arguments. The actions involved in (6a-c) are bidirectional and hence reciprocal; the verb / Daraba: / 'hit' in (6a) is extrinsically reciprocalmarked, with the use of the anaphor /baSDahuma: PalbaSD/ 'each other'; the verb /taDa:raba:/'TA.hit' in (b), which has the morphological marker /ta-/ is also capable of expressing a reciprocal meaning. It is worth noting that MSA allows both lexical and syntactic reciprocalization to appear in the same clause, as shown in (6c) where the morphologically reciprocalized verb / taDaaraba:/'TA.hit' and the reciprocal anaphor /baSDahuma: PalbaSD/ 'each other' are combined.

As far as Case and thematic marking are concerned, the predicate/ Daraba:/ "hit" in (6a) has an NP complement (its internal argument: /baSDahuma: PalbaSD/ 'each other' to which it assigns accusative Case and Theme. By comparison, the predicate /taDaaraba:/' in (6c) has a PP complement but the NP within the PP counts as the internal argument. Following Reinhart and Siloni (2005), I will assume that a PP complement here arises because of the morphological marking (the prefix /ta-/) on the verb that 'absorb' accusative Case. The verb as a result is incapable of assigning a structural Case to its internal argument, but /baSDihima: PalbaSDi/ 'each other' is assigned genitive Case by the preposition /maSa/ 'with'. The verb however still theta-marks its internal argument (NP within PP) with Theme as the preposition has no thematic content whatsoever (cf. Reinhart and Siloni (2005), Reinhart and Reuland (1993)).

Regarding the lexical encoding of reciprocality in MSA, it may involve only nominal elements as in /Mustafa wa Gumarun Paxawa:ni/ 'Mustafa and Omar are brothers.' ' (Implied meaning: Mustafa is Omar's brother and vice versa), or a modifier as in /Mustafa wa Sumarun yuða:kira:ni maSan/ 'Mustafa and Omar are studying together'(Implied meaning: Mustafa is studying with Omar and vice versa.)

Reciprocality can also be linguistically expressed in MSA by using multiple sentences as in/Palwaladu ra?a: Palbinta wahija raPathu/'The boy saw the girl and she saw him.' This strategy involves at least two predicates. However, this strategy is less common in languages such as English and Arabic wherein mutuality can be expressed in one proposition or clause; this is perhaps due to reasons of economy. The following table summarizes the structural typology of reciprocals in English and MSA:

TABLE 2

TYPOLOGY OF RECIPROCALS IN ENGLISH AND MSA

\begin{tabular}{|c|c|c|c|}
\hline \multirow[t]{6}{*}{ Single Proposition } & $\begin{array}{l}\text { Linguistic } \\
\text { elements in } \\
\text { English }\end{array}$ & Linguistic elements in MSA & Modes of linguistic encoding \\
\hline & Nominal & Nominal & \multirow[t]{2}{*}{ Lexical } \\
\hline & $\begin{array}{l}\text { Verbal elements } \\
\text { meet-fight }\end{array}$ & - & \\
\hline & - & $\begin{array}{l}\text { Collectivizing morphemes } \\
\text { inducing reciprocality } \\
(t a-,-t-)\end{array}$ & Morphological \\
\hline & $\begin{array}{l}\text { Reciprocal } \\
\text { anaphor } \\
\text { other }\end{array}$ & $\begin{array}{l}\text { Reciprocal anaphor /baSDahum } \\
\text { PalbaSD/ }\end{array}$ & \multirow[t]{2}{*}{ Syntactic } \\
\hline & $\begin{array}{l}\text { Reciprocal } \\
\text { Modifier together }\end{array}$ & $\begin{array}{l}\text { Reciprocal Modifier } \\
\text { /maSan/ }\end{array}$ & \\
\hline Multiple propositions & $\begin{array}{l}\text { Using the same } \\
\text { predicate }\end{array}$ & Using the same predicate & Syntactic \\
\hline
\end{tabular}

The aforementioned discussion summarizes the structural variations of reflexives and reciprocals in English and MSA. While the encoding of reflexivity and reciprocality in MSA is similar to that in English in many ways, there is some interesting and important variation between them at all of the morphological, syntactic, and semantic levels.

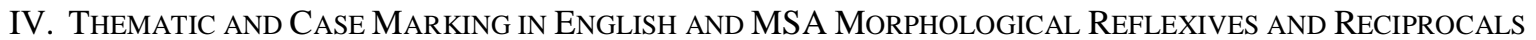


Morphological reflexive constructions are one-place unergatives (syntactically intransitive,), but semantically they are dyadic predicates as both semantic roles of the base root are syntactically encoded (Dimitriadis, 2004; Reinhart \& Siloni, 2005; and Dimitriadis \& Everaert 2014, among others). Reinhart and Siloni (2005, p. 400) claim that a bundled reflexive role is assigned to a single NP argument; but they write that the bundled roles must be dissociated in semantics. To capture this, Reinhart and Siloni argue that the reflexivization operation allows the assignment of two theta roles to the same syntactic slot by way of a process called bundling. They assume that such an operation is enforced by the $\theta-$ criterion requirement that thematic information carried by the verb be assigned. It is worth noting that Rákosi (2008) who uses the term 'argument-unification' proposed the same operation under another name. Consider the following example taken from (Reinhart \& Siloni, 2005, p. 401)

(7) a. Max washed.

b. Verb entry: wash.acc [Agent] [Theme]

c. Reflexivization output: wash [Agent+Theme]

d. Syntactic output: Max [Agent+Theme] washed.

As shown above, the bundling operation enables the assignment of two theta roles [Agent+Theme] to one syntactic argument (the subject, Max) with the fusion of the internal $\theta$-role (Agent) with the external $\theta$-role (the theme). Reflexivization also entails that the accusative Case is absorbed.

As is the case with reflexives, morphological reciprocal constructions are syntactically intransitive but semantically transitive (Reinhart \& Siloni 2005; Siloni 2008; 2012). In the reciprocalization operation, the $\theta$-role of the complement domain is also associated with the external $\theta$-role, and this association between the two $\theta$-roles is interpreted as a reciprocal relation since the resulting bundling renders the predicate symmetric. This is illustrated in (8)

(8) a. John and Mary kissed.

b. Verb entry: kiss [Agent] [Theme]

c. Reciprocalization output: kiss $\mathrm{SYM}$ [Agent+Theme]

d. Syntactic representation: John and Mary [Agent+Theme] kissed ${ }_{\mathrm{SYM}}$.

(Reinhart \& Siloni, 2005, p. 401)

Apparently, Reinhart \& Siloni (2005) and Siloni (2012) seem to consider that MSA morphological reflexives and reciprocals are straightforwardly reducible to those in English, in which the anaphor in both morphological reflexives and reciprocals may either be present or absent syntactically (e.g., he washed (himself); they met (each other)). In other words, they have failed to take into consideration the asymmetric relationship between morphological reciprocals and morphological reflexives in (9) and (10) below:

(9) a. / Palwaladu Pistahamma/.

The boy.NOM ST.bathed

'The boy bathed.' (= 'The boy bathed himself.')

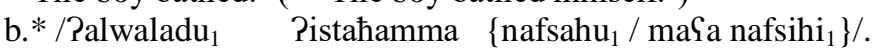

The man.NOM ST.bathed himself with himself.GEN

(10) a. / Pal Pawla:du <1+2> taqa:balu:/

The boys.NOM TA.met

b. //Pal Pawla:du $<1+2>$ taqa:balu: maSa baSDihim PalbaSDi $<1 \leftrightarrow 2>/$.

The boys.NOM TA.met with some.pl.GEN some.def.GEN

'The boys met with each other.'

In (9a), the verb is syntactically intransitive as no object can be added once /IST-/ appears with the verb hence the ungrammaticality of (9b) where the self-anaphor /nafsahu 1 / 'himself' appears as a complement of the verb.. The only argument in this sentence, / Palwaladu/ 'the boy' is conceived as being an Agent and Patient at the same time.

Unlike morphological reflexives, morphological reciprocals can take an overt reciprocal anaphor as a complement if it is within a PP complement as in (10). Thus, we can say that the affix (morphological marker on the verb) and the selfanaphor in (9b) are in complementary distribution, while the affix and the reciprocal anaphor in (10b) are not.

As shown above, there is a reflexive-reciprocal asymmetry in MSA with regard to the possibility of combining verb morphology with an overt anaphor. Given the above asymmetry in Arabic, I propose the following:

a. Morphological reflexive verbs project only one syntactic argument (the external argument).

b. Morphological reciprocal verbs project two syntactic arguments (the external and internal arguments). Consider the following examples:

(11) a. / Palwaladu Pintahara bisababi tawbi:xi PSdiqa:?ihi (*nafsihi)/ the boy.NOM committed suicide because rebuke friends-his. *himself.3ms

'The boy committed suicide because of the rebuke of $\{$ his friends/*himself

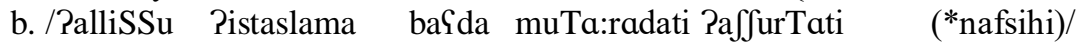
the thief.NOM ST.surrendred after pursuing.GEN the police-GEN *himself.3ms

'The thief surrendered after pursing the police'

c. / Palwaladu taSallama min PaxTa:ihi (*nafsihi)/ the boy.NOM TA.learned from mistakes.gen.his *himself.3ms

'The boy learned from his mistakes'. 
The examples in (11) are grammatical without the self-anaphor, but ungrammatical with self-anaphor (*nafsihi)/'himself'. That is because morphological reflexive verbs do not syntactically project an implicit internal argument by which the reflexive anaphor within the adjunct prepositional phrase can be anteceded and bound. Such verbs project a subject but not an object. Therefore, they cannot be followed by adjunct PPs containing unbound selfanaphors since this violates Principle A of the Binding Theory.

As far as Case marking is concerned, it is straightforward in sentences with morphological reflexive verbs. There is only one external argument projected syntactically, as demonstrated above, and this argument is assigned a nominative Case.

The following examples show that a morphological reciprocal verb always selects a syntactically realized anaphor as its internal argument, whether it may be realized overtly or covertly.

(12) a. / Pal Pawla:du $\langle 1+2\rangle$ taSaawanuu maSa baSDihim PalbaSDi $i_{<1 \leftrightarrow 2>} /$.

The boys3mpl.NOM TA.helped with some.pl.GEN some.def.GEN

'The teachers helped each other.'

b. / PalPawla:du $<1+2>\quad$ taSa:wanu: $\left[\mathrm{e}_{<<1 \leftrightarrow 2>}\right.$.

The boys.3mpl.NOM TA.helped

'The boys helped each other.'

The syntactic instantiation of the implicit argument ([e]) in (12b) in MSA reciprocal construction can be confirmed if we consider binding in sentences with PP complements, as demonstrated in (13) and (14).

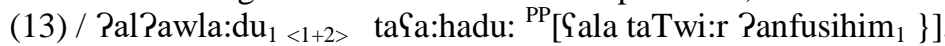

The boys.3mpl.NOM promised.TA on improvement themselves.3p-m-pl

'The boys promised each o ther the improvement of themselves.'

(14) / Pal Pawla:du ${ }_{1<1+2>}$ taSa:hadu: maSa Pabi:him 2 the boys $3 \mathrm{mpl}$.NOM TA.promised with father3ms.their.GEN

${ }^{\mathrm{PP}}$ [Sala taTwi:ri $\left\{\right.$ nafsihi $_{2} / \quad *$ Panfusihim 1$\left.\}\right] /$.

improvement himself. $3 \mathrm{~ms} / *$ themselves. $3 \mathrm{mpl}_{1}$

'The boys promised their father the improvement of $\{$ himself/ *themselves $\}$.'

The verb /taSa:hadu:/ 'TA.promised' in (13) that passed the binding test is morphologically marked with /ta-/. Verbs of this form are productively used to denote reciprocality. The self-anaphor /Panfusihim/ 'themselves' in the PP complement in (13) is supposedly bound by the implicit argument ([e]: the antecedent) which I claim to be syntactically present. This claim gains support if we consider the observation that the internal argument / Pabi:him /'their father' of the morphological reciprocal verb in (14) is the antecedent of the singular self-anaphor /nafsihi/ ' 'himself' within PP. If we try to interpret the self-anaphors in question to be bound by the plural subject arguments, then ungrammaticality arises, as can be shown by the failure of */Panfusihim ${ }_{1} /$ themselves'. Crucially, this suggests that / Panfusihim/ 'themselves' in (14) cannot be bound directly by the plural subject / PalPawla:du 〈1+2> 'the boys' but by the internal argument [e].

As far as Case marking is concerned, there is a difference between intrinsic reflexive and intrinsic reciprocal verbs only when the internal argument of the latter (the reciprocal anaphor) is overt. The case with morphological reciprocal verbs whose theme argument is overt is nevertheless treated differently. The subject argument /PalmuSallimu:na/'the teachers" in (15a) is theta-marked with Agent and Case-marked with nominative by the finite T. However, the complement argument / PaTTa:lib/ the student.3ms.GEN' is theta-marked by the predicate with theme. Although the NP / PaTTa:lib/ 'the student' shows up in the PP and is assigned genitive Case by the preposition/ maSa/'with', it is still interpreted as the internal argument of the verb because the preposition cannot have any thematic content. The sole function of this preposition is to assign structural Case, as assumed by Reinhart and Reuland (1993, p. 686) and Reinhart and Siloni (2005, p. 428)). If the preposition is omitted as in (15b), then ungrammaticality arises.

The examples in (15) also lead to the same conclusion:

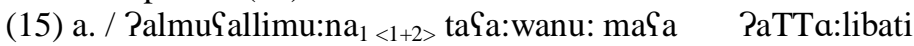

The teachers.3mpl.NOM ta.helped with the female student.3fs.GEN

${ }^{\mathrm{PP}}$ [Gala taTwi:ri \{ nafsiha: 2 / * Panfusihim 1 \}]/.

Improvement herself.3fs/ *themselves. $3 \mathrm{mpl}_{1}$.

'The teachers helped the female student with the improvement of \{herself/

*themselves \}.

b. / PalmuSallimu:na $<1+2>$ taSa:wanu: maSa PaTTula:bi

the-teachers.3mpl.NOM TA.helped with the students.3mpl.GEN

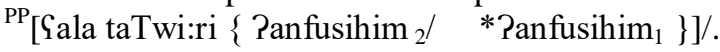

improvement themselves $2.3 \mathrm{mpl} /$ themselves $_{1} .3 \mathrm{mpl}$

'The teachers helped the male students with the improvement of $\left\{*\right.$ themselves $\left._{1}\right\}$.

c. / PalmuSallimu:na $<1+2>$ taSa:wanu: maSa PaTTa:liba:ti

the teachers.3mpl.NOM TA.helped with the female students.3fpl.GEN

${ }^{\mathrm{PP}}$ [Sala taTwi:ri \{ Panfusihinna $_{2}$ *Panfusihim1 \}]/

improvement $\{$ themselves.3fpl *themselves.3mpl\}. 
'The teachers helped the female students with the improvement of $\left\{\right.$ themselves $_{2} *$ themselves $\}$.

In the examples above, we observe that there is parallelism with respect to binding; i.e., it is the implicit argument [e] rather than the subject / PalmuYallimu:na/ 'the teachers' that binds The self-anaphors in the adjunct PPs .

By running on the binding test on morphological reciprocal verbs marked with /ta-/, it appears that a phonetically null argument is syntactically present (indicating that it is this empty internal argument rather than the external NP that binds the reflexive pronoun in the adjunct PP. This observation supports the hypothesis that morphological verbs syntactically project two arguments, one overt subject argument and one phonetically null but syntactically realized. The latter can in fact be overt, as we have seen earlier. In that case, the Agent-role is assigned to the subject, while the Theme-role is associated with the overt or covert argument.

To sum up, morphologically encoded reflexives are in fact syntactically and semantically asymmetrical in MSA. It will be argued that morphologically encoded reflexives do not project an anaphor (an internal argument) syntactically and their morphological marker semantically serves as a reflexivizer, whereas morphologically encoded reciprocals do project an anaphor syntactically, realized either overtly or covertly. The distribution of reflexives and reciprocals is illustrated in the following section.

\section{THE Distribution OF REFLEXIVES AND RECIPROCALS IN ENGLISH AND MSA}

This section investigates the binding domains for reflexive and reciprocal anaphors. One of the most influential proposals for the distribution of reflexives is Chomsky's (1991) Binding Theory (BT), which requires anaphors be bound within their binding Domain. Anaphors are usually characterized as expressions that have no inherent capacity for reference as they depend on another form for reference. This dependency is the motivation for assuming that anaphors have a particular set of distribution requirements. Binding means co-indexed and c-commanded. Structural binding domains for anaphors can be categorized into two groups: the local domain (for short-distance binding) wherein an anaphor is bound by the minimal (closest) accessible NP-subject. In addition, the extended domain (for mediumdistance binding) wherein an anaphor is bound by an NP-subject within Tense Phrase (TP) Koster \& Reuland (1991, p.10).

MSA allows all of short-distance, medium-distance, and long-distance binding, but does not allow the unbound use of anaphors for reasons that I will discuss later in this section. Consider the following examples:

(16) a. / Palbintu qatalat nafsaha:/*nafsahu/

The girl.NOM killed herself/*himself

"the girl killed herself /*himself"'

b. / Ralbana:tu qatalna baSDahunna PalbaSD/ *baSDahum PalbaSDa/ the girls.nom killed some.fpl.ACC some.def.ACC/*some.mpl.ACC some.def.ACC

"The girls killed each other."

As shown above, the anaphors /nafsaha:/'herself' and /baSDahunna PalbaSDa/ 'each other' are anteceded by the first accessible binder, as seen above.. If the anaphor is not anteceded by and co-referential with a binder, then ungrammaticality arises because of the violation of Principle A of the Binding Theory, as indicated by the starred anaphoric elements in (16a) and (16b). It is worth noting that Binding in such examples is subject-oriented. However, there are other cases where short-distance binding is possible but not obligatory, as illustrated by the following examples:

(17) a. / alwaladu $_{1}$ sa?ala Palbinta 2 San nafsiha: $2 /$ nafsihi $_{1} /$

The boy.NOM asked the girl.ACC about herself/himself

'The boy asked the girl about herself/himself.'

b. / Ral Pawla:du saPalu: Palbana:ti $_{2}$ San baSDahunna PalbaৎDa

the boys.NOM asked the-girls.ACC about some.fpl.ACC some.def.ACC

/baSDahum ?albaSDa/1

/some.mpl.ACC some.def.ACC

'The boys asked the girls about each other.'

The sentences above contain a matrix clause followed by a prepositional phrase.

These examples exhibit some degree of flexibility with respect to anaphoric binding; the reflexive pronouns may be either bound by the subject or object. The sentences in (17a) and (17b), unlike those in (16), do not strictly follow local binding when the anaphors are bound by the subjects. When this phenomenon occurs, we no longer have short-distance binding, but rather medium-distance binding.

MSA also allows long-distance binding where a reflexive anaphor inside a finite clause can be bound by an NP outside the clause. However, such long-distance binding is permissible only if the subject of the embedded finite clause is an expletive or if there is an overt NP following the expletive whose interpretation is referentially dependent on the matrix subject, as exemplified in

(18) a. /[TP Palbintu taStaqidu $_{\mathrm{CP}}\left[\right.$ Pannahu min PaSSaSbi PiSla:ha nafsiha: $\left.\left.{ }_{1}\right]\right] /$ the-girl.NOM think that-it from the-difficulty edification herself.GEN

'The girl thinks that it is difficult to edify herself.'

b. /[ TP $_{\text {Palbintu }}$ taStaqidu $_{\mathrm{CP}}\left[\right.$ Pannahu min PaSSaSbi PiSla:ha nafsihi $\left.\left.{ }_{1}\right]\right] /$ 
the-girl.NOM think that-it from the-difficulty edification himself.GEN

'The girl thinks that it is difficult to edify himself.'

(19) a./[TP Palbintu taStaqidu $_{\mathrm{CP}}\left[\right.$ Pannahu min PaSSaSbi Salajha: ${ }_{1}$ PiSla:ћa

The girl.NOM think that it from the difficulty for her edification

nafsiha: $\left.{ }_{1}\right]$ /

herself.GEN

'The girl thinks that it is difficult for her to edify herself.'

b. /[TP Palbintu $_{1}$ taStaqidu $_{\mathrm{CP}}$ [Pannahu min PaSSaSbi Salajhi 2 PiSla:ha nafsihi $\left.{ }_{2}\right]$ /

the-girl.NOM think that-it from the difficulty for him edification himself.GEN

'The girl thinks that it is difficult for him to edify himself.

As seen in (18a-b), there are two tensed clauses: a verbal clause and a nominal clause. The sentence in (18a) is grammatical even when it seems to involve long-distance binding; i.e., the subject /Palbintu/ 'the girl' of the matrix clause binds the reflexive pronoun /nafsiha:/' herself' in the subordinate clause. In comparison, (18b) with the indicated indices is ungrammatical due to the violation of Principle A, /nafsihi/'himself' not having a binder in its binding domain. (18b) is evidence against the presence of PRO. If the postulation of PRO is correct, then (18b) would predictably be well formed, but it actually is not, which provides evidence for long-distance binding in (18a).

Both (19a) and (19b) are grammatical as the expletive / Panna/ 'that' is followed by an overt NP that is co-referent with matrix subject. If the expletive is replaced by another NP that is disjoint in reference from the matrix subject, then the anaphor in the embedded clause must be anteceded by the closest NP; otherwise, ungrammaticality arises, as shown in (20) below:

(20) /[TP Palbintu $_{1} \quad$ taStaqidu $_{\mathrm{CP}}\left[\right.$ Panna Palwalada 2 ma/Vu:lun biPiSla:hi nafsihi ${ }_{2 / *}$ nafsiha: $\left.\left.{ }_{1}\right]\right] /$

the-girl.NOM think that the boy busy edification himself/*herself.GEN

'The girl thinks that the boy is busy with edifying himself/*herself.

The above sentence is acceptable only if the anaphor is locally bound; otherwise, it is unacceptable.

Long-distance binding in reciprocals is also permissible in similar environments, on par with reflexives.

Thus far, we have seen that reflexive or reciprocal anaphors may be locally or non-locally bound (short-distance vs. medium- and long-distance binding). If we closely look at all the examples given above, we will find that such anaphors not only are subject to Principle A, but also must be in a complement position, whether it be a direct object of a verb or verbal noun, or an object of a preposition. Since reflexive and reciprocal anaphors in MSA seem to be allowed only in a position where they are assigned accusative Case (by a verb) or genitive Case (by a preposition or the D position occupied by a verbal noun), we may be able to say that no reflexive or reciprocal anaphors can occupy a nominative subject position in MSA. The ungrammaticality of the examples in (21) and (22) indeed suggests that this is a correct generalization

(21) */Palbintu 1 lam tadri: ma:ða: nafsha: faSalat/ the-girl.NOM not know what herself did

*'The girl did not know what herself had done.'

(22)*/Palbintu 1 wa Palwaladu 2 lam jadrija: ma:ða: baSDuhuma:/

The girl.NOM and the boy.NOM not know what some.mpl.GEN

PalbaSD $<1 \leftrightarrow 2>$ faSala:/

some.def.GEN did

* 'The girl and the boy did not know what each other had done.'

The ungrammaticality of the examples above is due to the fact that both the reflexive /nafsha:/ 'herself, and the reciprocal /baSDuhuma: PalbaSD/' 'each other' occur in the subject position. They do not have a clause-mate antecedent. We can see that the reflexive anaphor in (21) and its reciprocal counterpart in (22) are symmetrical with respect to not being able to appear in a subject position.

\section{OVERRIDE REFLEXIVES AND RECIPROCALS IN ENGLISH AND MSA}

This section focuses on the override usage of reflexive and reciprocal anaphors. But before we discuss override anaphor in MSA, let us see why override are called as such and how they differ from regular anaphors.

Override reflexives and reciprocals have often been categorized as exceptions to the Chomsky's (1981) binding domains, reserved to footnotes, or completely ignored. They have confusingly been labelled many different terms like 'long-distance-bound reflexives' (Zribi-Hertz, 1989), 'untriggered reflexive pronouns' (Parker et al., 1990), 'logophors' (Reinhart \& Reuland, 1991, 1993), 'locally free reflexives' (König \& Siemund, 2000) and 'semi-emphatic reflexive pronouns' (Quirk, 2010), in an attempt to analyze and interpret their occurrences..

Not all of these notions are equivalent, but all of them refer to occurrences of reflexives and reciprocals that violate the binding domains lacking any close structural relation between them and the antecedent (Sørensen,S. 2019, p. 20). According to Huddleston \& Pullum (2002), 'override reflexive' occurs in places where a pronominal should have been used. In general, they refer to reflexives that co-refer with nominal expressions outside the local domain of the minimal clause. 
The contexts licensing the occurrence of these override self-forms in English have triggered a new vein of research. There are essentially two types of contexts, which license override reflexives. The first context is that override anaphors need to be anteceded by perspective centers. In other words, it has been observed that English self-expressions have distinct characteristics in the context of verbs of saying and perceiving as shown in the following example (adapted from Pollard and Sag 1992):

(23) Bill said that the rain had damaged pictures of himself.

In the above example, reflexive himself does not have a co-argument. However, the grammaticality of such sentences crucially depends on himself being in association with the subject of the verb say, Bill. The one referring to the center of perspective.

The other context is the contrastive one. Huddleston and Pullum (2002) list the following environments and corresponding examples for override reflexives:

(24) a. coordination: 'Ann suggested that the reporter pay both the victim and herself for their time'.

b. comparatives: 'They were all much better qualified than myself'.

c. inclusion/exclusion: Everybody, including yourself, will benefit from these changes. 'Liz could not understand why nobody except herself had complained'.

d. as for: 'As for myself, it doesn't worry me which one they choose'.

e. how about: 'I enjoyed it-how about yourself'?

f. complement of be: 'The only one they didn't invite was myself'.

g. complement of a preposition in predicative complement function: 'All Ann's novels are really about herself'.

Unlike English, MSA behaves differently with such constructions. It does not allow unbound reflexives. Reflexives in MSA must be bound regardless of whether or not they are part of the predicate-argument structure, and their reference cannot be provided discoursally as in the following examples:

(25) a. */Palwaladu ra?a: [NP Su:ratan linafsi:]/.

theboy.NOM saw picture of myself.GEN

'The boy saw a picture of myself.'

b. /*?alwaladu daSa: Palbinta wanafsi: lilhaflati/

The boy.NOM invited the girl.ACC and myself to the party.GEN

'The boy invited the girl and myself to the party.'

The examples in (25a) and (25b) show that MSA override reflexives, unlike their English counterparts, are syntactically restricted in accordance with Principle A. Reflexives and reciprocals are in fact syntactically and semantically asymmetrical.

While MSA disallows reflexive possessives, namely, constructions consisting of a noun or locative preposition and a reflexive pronoun, it allows reciprocal possessives as illustrated by the following examples.

(26) * Palwaladu ra?a: [NP Suwara nafsihi ${ }_{1}$.

The boy.NOM saw pictures himself.GEN

'The boy saw himself's pictures'.

(27) PalPawla:du $<1+2>$ raPu: [NP Suwarata baYDihim PalbaSD $<1 \leftrightarrow 2>$ ]

The boys.NOM saw pictures some.mpl.GEN some.def.GEN

'The boys $<1+2>$ saw each other' $s<1 \leftrightarrow 2>$ pictures

The sentences in (26) and (27) are asymmetrical in both "reflexives and reciprocals"'in MSA. This distributional difference between MSA reflexives and reciprocals needs to be accounted for. Reuland (2011, pp.167-169) observes that there is an interesting correlation between definiteness marking and the availability of a dedicated reflexive possessor in a language. He classifies languages into two groups:

(i) Languages having reflexive possessives either lack definiteness marking or encode definiteness post nominally, such as Czech, Danish, Icelandic, Norwegian, Polish, Romanian, Swedish, Russian, and other Slavic languages.

(ii) Languages lacking reflexive possessives mark definiteness by using a prenominal article, such as Dutch, English, French, German, Italian, and Modern Greek.

MSA patterns up with English in having prenominal definite articles / Pal/ 'the', thus lacking dedicated reflexive possessors. Despić (2015) takes the classification of the two different groups of languages just given as a point of departure in order to account for the ungrammaticality of reflexive possessives versus the grammaticality of reciprocal possessives in English. Despić's account rests on the following three assumptions: (i) binding domains are phase-based, (ii) DP's are phases, and (iii) the DP is not universal (see, among others, Bošković $(2005,2014)$ ).

MSA and English have a DP layer in the possessive noun phrase. D is a phase head when taking PossP as its complement and thus constitutes a binding domain, just like vP and CP (Despić 2015, p. 211). 


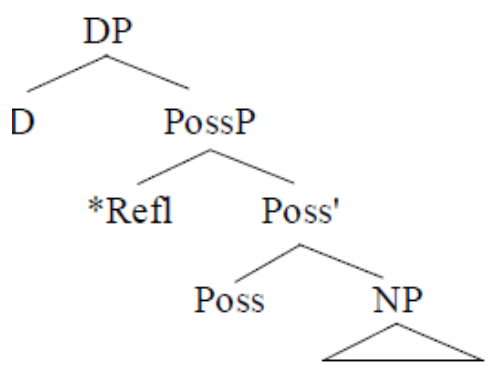

Since DP constitutes its binding domain in DP languages, the reflexive anaphor in Spec of PossP cannot be bound in its binding domain. The dependency between the possessive pronoun and its antecedent is not local therefore, and, for the same reason, no special anaphoric reflexive possessor is licensed. In contrast, reciprocal anaphors can occur within DP, as illustrated in (42) below. ((42a-d) are from Despić 2015: 213).

(29)

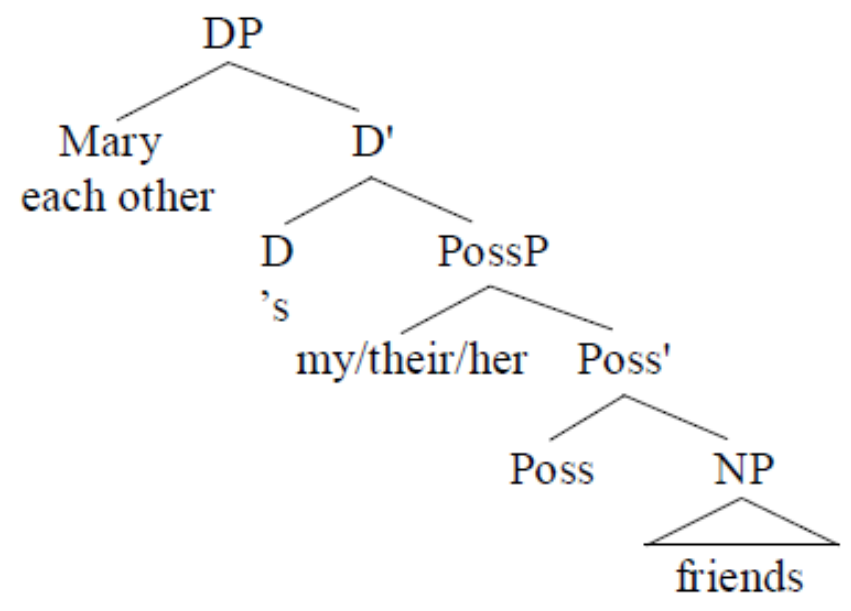

(30) a. Mary's friends.

b. each other's friends.

c. *their's friends.

As seen above, reflexive pronouns and reciprocals are licensed in different structural positions; namely, the reflexive occupying Spec of PossP, while the reciprocal occupying Spec of DP. That possessive lexical DPs (non-pronominal DPs) and possessive reciprocals pattern together in English as they are both licensed in a structural position higher than the position occupied by pronominal possessors, as seen in (29). Since non-pronominal possessive DPs possessive reciprocals are positioned at the leftmost edge of DP phase, unlike reflexive possessives that are positioned lower than the D head as in (28), reciprocals can then be bound within the vP domain containing this DP, an analysis which accounts for the grammaticality of reciprocal possessives and the ungrammaticality of reflexive possessives in Englishtype languages.

Based on Despić's (2015) assumption concerning English reflexive and reciprocal possessives, the reflexive reciprocal possessive asymmetry in MSA can be accounted for as such since MSA patterns with English in this regard, as illustrated by the following examples.

(31) Suwara baৎDihim PalbaৎDi pictures some.mpl.GEN some.def.GEN 'each others' pictures'

(32) each other's pictures

Given that the possessor-possessum hierarchical relation in MSA is different from that in English, there is still another independent issue in MSA that requires explanation and needs to be worked out. In MSA, possessive constructions, the possessum precedes the possessor as in (44), whereas in English the possessum follows the possessor as in (45) above. The question arising here is how the structure in (44) can be explained; i.e., how can we account for the grammaticality of reciprocal possessives versus the ungrammaticality of reflexive possessives in MSA.

In MSA, there is a noun phrase called a construct-state in which there is a noun raising to D which, like INFL, may assign a genitive Case to the subject of the construct-state (Carnie, 2012) as illustrated in the following tree diagram: 
(33) a.

Pre-movement

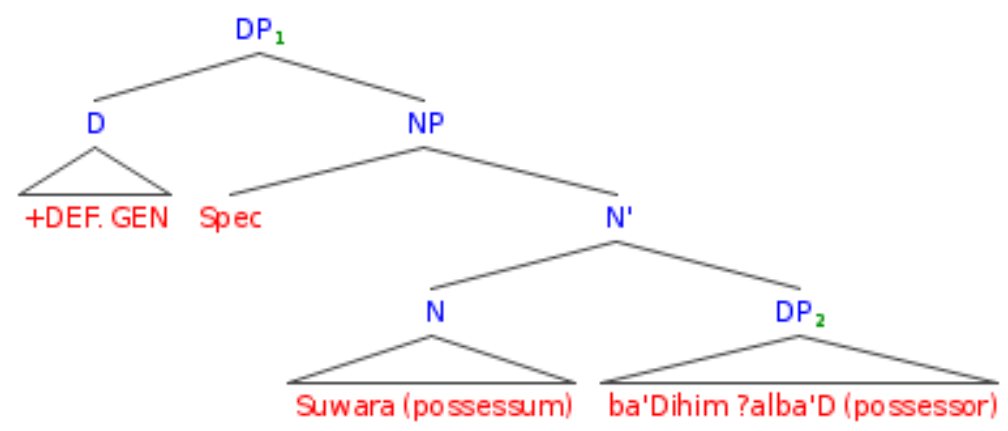

b.

Post movement

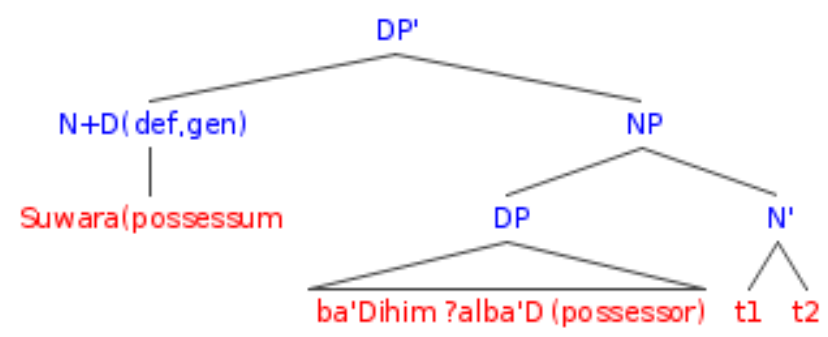

The D in (33a) contains two morphemes: definiteness (DEF) and a Case assigner (GEN); the DP is definite whenever $\mathrm{D}$ is [+ DEF]. Given that, since /Suwara/ 'pictures' is not a Case assigner, the complement /baSDihim PalbaSD/ 'each other' cannot be assigned structural Case in situ and therefore moves to Spec of NP in order to be Case-marked with GEN. Since the Case-assigner needs to be supported morphologically, a movement of the N head to the D head is also required (Ritter 1988: 922), as indicated in (33b). This structure provides a syntactic analysis for construct-states in MSA.

\section{LOCATIVE POSSESSIVES}

In MSA, reflexives and reciprocals can both be an object of preposition, as illustrated before. However, this is not the case if these two types are preceded by locative prepositions, as exemplified below:

(34) a. Palwaladu ${ }_{1} \quad$ waDaPa Suwaran [ ${ }^{\mathrm{PP}}$ Pama:mahu $1^{-} \quad$ xalfahu $_{1}$-tahta-hu $\left.{ }_{1}\right]$

The boy.NOM put pictures in front of-behind- under him

'The boy put pictures in front of-behind-under him'.

b. Palwaladu ${ }_{1}$ waDa?a Suwaran [*?ama:ma *xalfa *tahta nafsihi ${ }_{1}$ ].

The boy.NOM put pictures in front of -behind-under himself.GEN

'The boy put pictures in front of-behind-under himself.'

(35) a. PalPawal:du 1<1+2> waDaPu: Suwaran [PPPama:mahum $_{1}-$ xalfahum $_{1}-$ tahtahum $_{1}$ ] the boys.NOM put pictures [ in front of- behind- under them].

'The boys put pictures in front of-behind-under them'.

b. PalPawal: $\mathrm{du}_{1}<1+2>$ waDa?u: Suwaran [?ama:ma- xalfa- tahta baSDihim

PalbaSD $<1 \leftrightarrow 2>]$.

The boys.NOM put pictures in front of some.mpl.GEN some.def.GEN

'The boys put pictures in front of- behind- under each other.'

The sentences in (34) and (35) exhibit asymmetry between MSA reflexives and reciprocals in locative prepositional phrases. In English, on the other hand, both reflexives and reciprocals are permitted in all constructions as the English translations of the MSA examples indicate. There are two intriguing questions arising here: why do we get this asymmetry in locative preposition, but not in regular prepositional phrases? And why is MSA different from English?

In MSA regular prepositional phrases, there is no PossP under DP to begin with and the DP does not count as a phase. Both reflexives and reciprocals are bound by an antecedent within vp.

The matter is different with locative possessives. We notice that possessive locatives are ungrammatical with the reflexives, and grammatical with reciprocals. Based on Despić (2015), I propose that there is a PossP within the DP under PP, which results in this asymmetry. In other words, locative prepositions in MSA form a possessive construction with their DP-complements, as the case in construct-state possessive constructions. 
a.

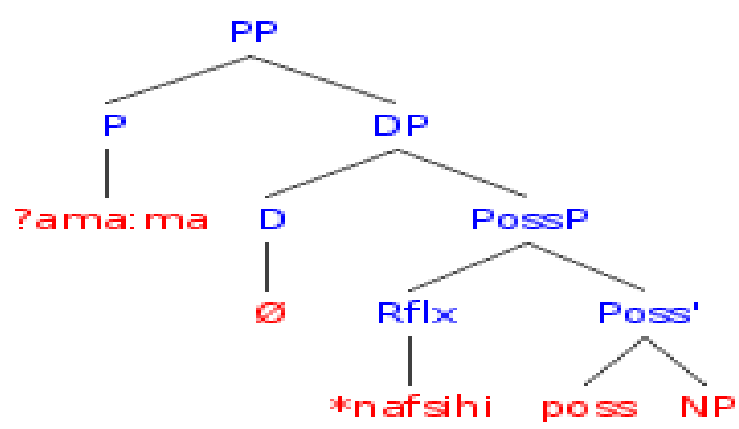

b.

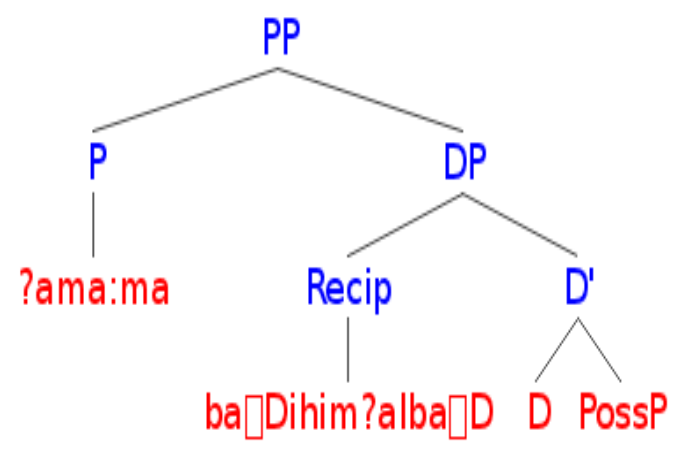

The tree diagram in (36 a) explains why the sentence in (34b) is ungrammatical. The reflexive /nafsihi/ "himself" is positioned lower than $\mathrm{D}$ head within the complement of $\mathrm{D}$. Therefore, it must be bound within its phase and hence binding domain; namely the DP. In (35b), the reciprocal /baSDihim PalbaYD/ 'some.mpl.GEN some.def.GEN' is located as a spec of the DP complement of the locative. It is higher than D head and it can seek an antecedent outside of the DP. Therefore, The DP is considered a phase. The PP here therefore is parallel to NP containing PossP.

The similarity between locative possessives and construct-state is evidenced-based. Locative prepositional phrases and its DP complement form a construct-state and hence a possessive construction, parallel to construct-states consisting of $\mathrm{N}$ and its DP-complement. In both constructions, the possessum assigns a genitive case to the possessor. The second is that the definite article has to be lowered to adjoin the closest maximal projection if the D is [+Def] (Ritter, 1988). Moreover; these locative prepositions can be object of true prepositions and can be adverbials (Ryding, 2005) as illustrated below:

TABLE 3

FEATURES OF LOCATIVE PREPOSITIONS

\begin{tabular}{|l|l|l|l|l|}
\hline Part of Speech & Bearing the definite article & Possessive & Object of preposition \\
\hline Locative Preposition & $\sqrt{ }$ & $\sqrt{ }$ & $\sqrt{ }$ & Adverbial \\
\hline Example & /Palxalf/ 'the behind' & $\begin{array}{l}\text { /xalf Palba:b/ } \\
\text { 'behind the door' }\end{array}$ & $\begin{array}{l}\text { /min /xalf Palba:b/ } \\
\text { 'From behind the door' }\end{array}$ \\
\hline
\end{tabular}

The above table shows that locative prepostitions share all features with nouns, which explains why both categories (nouns and locatives) cannot co-occur with reflexive anaphors because the noun or locative plus a Self anaphor forms a reflexive possessive which is ungrammatical in MSA, as seen earlier. Concerning the second question (why is MSA different from English in this respect?), the answer to this question is that MSA locative prepositional phrases, unlike their English counterparts, constitute possessive constructions when paired with their DP complements. Consequently, English PPs like' in front of himself' and 'in front of each other' are symmetrical and both allowable, while MSA PPs like*/Pama?ma nafsihi/ 'himself's front' (in front of himself) and / Pama:ma baSDihim Pal-baS/ 'each other's front' (in front of each other) are asymmetrical and only the reciprocal is allowable.

To sum up, the distribution of reflexive anaphors in MSA is much more restricted than that of reciprocal anaphors; the latter, unlike the former, may occur in possessive constructions such as the construct-state, whether it be a noun phrase or a locative prepositional phrase. This variation is attributed to the assumption that reflexive and reciprocal anaphors occupy different structural positions in possessive constructions (phases) and only the reciprocals can be bound by an NP from a higher phase, whereas reflexives occupy a position lower than the D head and thus must be bound within their DP phase.

\section{CONCLUSION}

In MSA, reflexives and reciprocals rely more on the syntactic and morphological encoding than on lexical encoding. Morphologically encoded reflexives in MSA, unlike syntactically encoded ones, are not subject to Principle A since they do not project any anaphoric objects to begin with. Syntactically encoded reflexive verbs and reflexive pronouns generally allow short-, medium- and long-distance binding. However, long-distance binding is only possible if the NP subject in the subordinate nominal clause is an expletive. MSA overrides reflexives, unlike their English counterparts, cannot be free.

There are two types of reciprocal constructions in MSA: constructions involving syntactically encoded verbs which project an overt reciprocal anaphor and those involving morphologically encoded verbs which project either a covert or an overt reciprocal anaphor. As far as binding domains are concerned, reciprocal anaphors in MSA are subject to short, medium-and long-distance binding, on par with reflexive anaphors. MSA reciprocal anaphors may also be used as overrides, just like their reflexive counterparts, as long as Principle A is not violated. Morphologically encoded reflexives and reciprocals exhibit asymmetries with respect to the number of arguments syntactically projected and the 
function of the morphological marker. The former verbs do not syntactically project an anaphor at all and their morphological marker semantically has as a reflexivizing function, while the latter do project an anaphor syntactically, whether covertly or overtly.

As far as reflexive and reciprocal anaphors are concerned, the former, unlike the latter, cannot be used in any possessive constructions, whether they involve nouns or locative prepositions. This discrepancy between reflexive and reciprocal possessives is ascribed to the assumption that reflexive and reciprocal anaphors occupy different structural positions in possessive constructions (phases) and only the reciprocals can be bound by an NP from a higher phase.

\section{APPENDIX A. READING CONVENTIONS}

The transcription used in this Paper is largely phonemic in nature. The following symbols used to transcribe Arabic examples are basically adapted from IPA with slight modification for typing reasons.

(1) Consonants

\begin{tabular}{|c|c|c|c|}
\hline \multicolumn{2}{|c|}{ Sound Phonological Descriptions } & \multirow{3}{*}{$\frac{\text { Example }}{\text { /ba:b/ }}$} & \multirow{3}{*}{$\frac{\text { Translation }}{\text { door }}$} \\
\hline & & & \\
\hline$ب / \mathbf{b} /$ & Voiced bilabial stop & & \\
\hline$ت / t /$ & Voiceless alveolar stop & $/ \mathrm{tamr} /$ & date \\
\hline b/T/ & Voiceless alveolar emphatic stop & /Tari:q/ & road \\
\hline $\mathrm{s} / \mathbf{d} /$ & Voiced alveolar stop & /di:n/ & religion \\
\hline ض/D/ & Voiced alveolar emphatic stop & /Da:biT/ & $\begin{array}{l}\text { Police } \\
\text { officer }\end{array}$ \\
\hline$s / \mathbf{k} /$ & Voiceless velar stop & /kita:b/ & book \\
\hline ق/ & Voiced uvular stop & /qalam/ & pen \\
\hline$\varepsilon / 2 /$ & Voiced glottal stop & /Pasad/ & lion \\
\hline $\mathrm{e} / \mathrm{m} /$ & Voiced bilabial nasal & /mu:zah/ & banana \\
\hline$ن / \mathbf{n} /$ & Voiced alveolar nasal & /nahlah/ & bee \\
\hline$J / 1 /$ & Voiced alveolar lateral & /laymu:nah/ & lemon \\
\hline $\mathrm{J} / \mathbf{r} /$ & Voiced dental trill & /rajul/ & $\operatorname{man}$ \\
\hline ف/f/ & Voiceless labiodental fricative & /fara: $\int \mathrm{ah} /$ & butterfly \\
\hline$ث / \mathbf{\theta} /$ & Voiceless dental fricative & /Өawb/ & cloth \\
\hline
\end{tabular}

\begin{tabular}{|c|c|c|c|}
\hline ذ/ð/ & Voiced dental fricative & /ðayl/ & tail \\
\hline 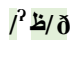 & Voiced inter-dental emphatic fricative & $\begin{array}{c}/ ð \\
\operatorname{arf} /^{?}\end{array}$ & envelope \\
\hline m/s/ & Voiceless alveolar fricative & /sa:Yah/ & watch \\
\hline$\sim \mathbf{S}$ & Voiceless alveolar emphatic fricative & $/ \mathrm{Sa \hbar n} /$ & plate \\
\hline$j / \mathbf{z} /$ & Voiced alveolar fricative & /zara:fah/ & giraffe \\
\hline ش/// & Voiceless palatal fricative & / Jajarah// & tree \\
\hline $\mathrm{e} / \mathrm{j} /$ & Voiced palatal affricate & /jamal/ & camel \\
\hline$\dot{\tau} / \mathbf{x} /$ & Voiceless velar fricative & /xaru:f/ & sheep \\
\hline$\dot{\varepsilon} / \mathrm{Y}^{\prime}$ & Voiced uvular fricative & /Vura:b/ & crow \\
\hline
\end{tabular}




\begin{tabular}{|c|l|c|c|}
\hline$\varepsilon / \mathbf{l} /$ & Voiced pharyngeal fricative & $/$ Gayn/ & eye \\
\hline $\mathrm{o} / \mathbf{h} /$ & Voiceless glottal fricative & $/$ haram/ & pyramid \\
\hline$\tau / \mathbf{h} /$ & Voiceless pharyngeal fricative & $/$ hama:mah/ & pigeon \\
\hline$g / \mathbf{w} /$ & Voiced bilabial glide & $/$ wardah/ & flower \\
\hline$s / \mathbf{y} /$ & Voiced palatal glide & $/ \mathrm{yad} /$ & hand \\
\hline
\end{tabular}

\section{(2)Vowels}

\begin{tabular}{|c|c|c|c|}
\hline Sound & Phonological Description & Example & \\
\hline$/ \mathbf{a} /$ & Short open, front, unrounded vowel & /katab/ & write \\
\hline /a:/ & Long open, front, unrounded vowel & /kita:b/ & book \\
\hline$/ \mathbf{a} /$ & Short open back unrounded vowel & /Sabr/ & patience \\
\hline$/ \mathbf{a}: /$ & long open back unrounded vowel & /Sa:bir/ & patient \\
\hline$/ \mathrm{i} /$ & Short close front unrounded vowel & /Pibn/ & son \\
\hline /i:/ & long close front unrounded vowel & /Pi:Өa:r/ & altruism \\
\hline$/ \mathbf{u} /$ & Short close back rounded vowel & /Pusa:mah/ & Osama \\
\hline /u:/ & Long close back rounded vowel & /funu:n/ & arts \\
\hline
\end{tabular}

\section{APPENDIX B. NOTES ON READING CONVENTIONS}

-Phonemic transcription will occur between two slashes / /.

-Allophones of /a/ include /a/, which is a short low back vowel, before emphatic consonants and /q/, /r/ $/ \mathrm{Y} /$ and $/ \mathrm{x} /$ (AlAni, 2008, p. 595).

-Elision concerns the omission under certain conditions of the short vowels $/ \mathrm{a} /, / \mathrm{i} /, / \mathrm{u} /$, on the one hand, and of $/ \mathrm{P} /$ (with or without accompanying vowel), on the other. Where elision of a vowel with / $/$ / occurs at the junction of a particle and a word, the feature has been marked in the writing by a hyphen (-). For example, /mana:hij PaltaSli:m/ becomes /mana:hij Pat-taSli:m/.

-Geminates are regularly transcribed as identical double consonants, e.g. , tt, dd, ss, etc.

\section{List of Abbreviations}

\begin{tabular}{|l|l|}
\hline Abbreviation & Term \\
\hline $1,2,3$ & First, second and third person \\
\hline ACC & Accusative case \\
\hline CP & Complementizer Phrase \\
\hline DP & Determiner Phrase \\
\hline F & Feminine \\
\hline GEN & Genitive case \\
\hline M & Masculine \\
\hline MSA & Modern Standard Arabic \\
\hline NOM & Nominative case \\
\hline NP & Noun Phrase \\
\hline PL & plural \\
\hline POSSP & Possessive phrase \\
\hline PP & Prepositional Phrase \\
\hline T & Tense \\
\hline TP & Tense Phrase \\
\hline$<1+2>$ & dual or plural subjects \\
\hline$<1 \leftrightarrow 2>$ & a reciprocal relation holding between the individual participants, indexed with \\
1
\end{tabular}

\section{REFERENCES}

[1] Bošković, Ž. (2005). On the locality of left branch extraction and the structure of NP. Studia linguistica, 59(1), 1-45. 
[2] Carnie, A. (2012). Syntax: A generative introduction (Vol. 18). West Sussex: John Wiley \& Sons.

[3] Chomsky, N. (1981). Lectures on Government and Binding (Dordrecht: Foris). Studies in generative grammar, 9.

[4] Chomsky, N. (2000). Minimalist inquiries: The framework (MITOPL 15). Step by step: Essays on minimalist syntax in honor of Howard Lasnik, 89-155.

[5] Despić, M. (2015). Phases, reflexives, and definiteness. Syntax, 18(3), 201-234.

[6] Dimitriadis, A. (2008). Irreducible symmetry in reciprocal constructions. In E. König \& V. Gast (Ed.), Reciprocals and Reflexives: Theoretical and Typological Explorations (pp. 375-410). Berlin, New York: De Gruyter Mouton. https://doi.org/10.1515/9783110199147.375

[7] Dimitriadis, A., \& Everaert, M. (2014). How many theta roles in a reflexive verb? Acta Linguistica Hungarica, 61(3), $247-269$.

[8] Gaby, A. (2008). Distinguishing reciprocals from reflexives in Kuuk Thaayorre: In E. König \& V. Gast (Ed.), Reciprocals and Reflexives: Theoretical and Typological Explorations (pp. 259-288). Berlin, New York: De Gruyter Mouton. https://doi.org/10.1515/9783110199147.259

[9] Heine, B. \& Miyashita, H. (2008). The intersection between reflexives and reciprocals: A grammaticalization perspective: In E. König \& V. Gast (Ed.), Reciprocals and Reflexives: Theoretical and Typological Explorations (pp. 169-224). Berlin, New York: De Gruyter Mouton. https://doi.org/10.1515/9783110199147.169

[10] Huddleston, R. \& Pullum, G. (2005). The Cambridge Grammar of the English Language. Zeitschrift für Anglistik und Amerikanistik, 53(2), 193-194. https://doi.org/10.1515/zaa-2005-0209

[11] Kemmer, S. (1993). The middle voice (Vol. 23). Amsterdam \& Philadelphia: John Benjamins

[12] König, E., \& Siemund, P. (2000). Locally free self-forms, logophoricity, and intensification in English. English Language \& Linguistics, 4(2), 183-204.

[13] Koster, J., \& Reuland, E. (Eds.). (1991). Long distance anaphora. Cambridge: Cambridge University Press.

[14] Ndimele, O. M. (1999). A first course on morphology and syntax. Port Harcourt: M. and J. Grand Orbit Communications.

[15] Parker, F., Riley, K., \& Meyer, C. F. (1990). Untriggered reflexive pronouns in English. American Speech, 65(1), 50-69.

[16] Quirk, R. (2010). A comprehensive grammar of the English language. England: Pearson Education India.

[17] Radford, A. (2004). Minimalist syntax: Exploring the structure of English. Cambridge: Cambridge University Press.

[18] Rákosi, G. (2008). The inherently reflexive and the inherently reciprocal predicate in Hungarian: Each to their own argument structure. In E. König \& V. Gast (Ed.), Reciprocals and Reflexives: Theoretical and Typological Explorations (pp. 411-450). Berlin, New York: De Gruyter Mouton. https://doi.org/10.1515/9783110199147.411

[19] Reinhart, T., \& Reuland, E. (1993). Reflexivity. Linguistic inquiry, 24(4), 657-720.

[20] Reinhart, T., \& Siloni, T. (2005). The lexicon-syntax parameter: Reflexivization and other arity operations. Linguistic inquiry, $36(3), 389-436$.

[21] Siloni, T. (2008). The Syntax of Reciprocal Verbs: An Overview: In E. König \& V. Gast (Ed.), Reciprocals and Reflexives: Theoretical and Typological Explorations (pp. 451-498). Berlin, New York: De Gruyter Mouton. https://doi.org/10.1515/9783110199147.451

[22] Siloni, T. (2012). Reciprocal verbs and symmetry. Natural Language \& Linguistic Theory, 30(1), 261-320.

[23] Sørensen, S., (2019). Override Reflexive Pronouns in English and Danish: An investigation and comparison [Master's thesis, Aarhus University] Retrieved from: https://tildeweb.au.dk/au132769/papers/Soerensen-2019-MA-diss-Override-Reflexives-inEnglish-and-Danish.pdf (accessed 29/10/2020).

[24] Stern, N. (2004). The semantic unity of reflexive, emphatic, and other-self pronouns. American speech, 79(3), 270-280.

[25] Wright, W., \& Caspari, C. P. (2011). A grammar of the Arabic language. New York: Cosimo, Inc..

[26] Zribi-Hertz, A. (1989). Anaphor binding and narrative point of view: English reflexive pronouns in sentence and discourse. Language, 65(4), 695-727.

Shaimaa I. Darwish earned her Ph.D. in comparative syntax and Linguistics at Al-Azhar University in Egypt in 2018. She earned her Master of Arts in minimalism from Ain Shams University in 2011. She obtained her Bachelor of Arts degree in English Language, Literature and simultaneous Translation from Al-Azhar University in 2005.

She is currently a lecturer of linguistics at Al-Azhar University. She has taught a variety of linguistic courses at the undergraduate level. Her research agenda lies in two main areas: comparative syntax particularly between English and Arabic, and applied linguistics, including second-language teaching and critical discourse analysis. She co-authored a paper entitled" Case Theory between Chomsky and Sibawayh: A minimalist Approach' 'in 2012. 